\title{
Il Avaliação e gestão do risco em organizações de saúde 12. Gestão do risco de quedas, úlceras por pressão e de incidentes relacionados com transfusão de sangue e hemoderivados
}

\author{
Paulo Sousa \\ Sílvia Oliveira \\ Ana Alves \\ Ana Teles
}

\section{SciELO Books / SciELO Livros / SciELO Libros}

SOUSA, P., OLIVEIRA, S., ALVES, A., and TELES, A. Gestão do risco de quedas, úlceras por pressão e de incidentes relacionados com transfusão de sangue e hemoderivados. In: SOUSA, P., and MENDES, W., comps. Segurança do paciente: conhecendo os riscos nas organizações de saúde [online]. 2nd ed. rev. updt. Rio de Janeiro, RJ : CDEAD, ENSP, Editora FIOCRUZ, 2019, pp. 263-293. ISBN 978-85-7541641-9. https://doi.org/10.7476/9788575416419.0015.

\section{International license.}

Todo o conteúdo deste trabalho, exceto quando houver ressalva, é publicado sob a licença Creative Commons Atribição 4.0. 


\section{Gestão do risco de quedas, úlceras por pressão e de incidentes relacionados com transfusão de sangue e hemoderivados}

Paulo Sousa, Silvia Oliveira, Ana Alves e Ana Teles

Neste capítulo, aprofundaremos a temática das quedas e das úlceras por pressão (também denominada de lesão por pressão) abordando, numa fase inicial, seus conceitos, suas causas, consequências, custos e medidas preventivas. Será, igualmente, referido alguns dos principais instrumentos de avaliação e ações a adotar após sua ocorrência. Ainda, neste capítulo, serão abordados os incidentes relacionados com a transfusão de sangue e hemoderivados, suas consequências, factores contribuintes e formas de diminuir ou evitar sua ocorrência.

Outras situações que colocam em risco a segurança dos pacientes, tais como tromboembolismo venoso; delirium, acidente vascular cerebral e enfarte/infarto agudo do miocárdio, como complicações pós-operatórias; a gestão/gerenciamento da dor, uso único para dispositivos de injeção, falhas de conexões, fadiga de alarmes e interrupção da enfermagem serão apresentadas de forma mais sucinta nos anexos ao final deste livro Segurança do paciente: conhecendo os riscos nas organizações de saúde.

\section{Quedas}

Uma queda, de acordo com a OMS (WHO 2012), é definida como um evento caracterizado pela descida abrupta do corpo para um nível inferior ao que se encontra, como solo ou pavimento. Para Almeida, Abreu e Mendes (2010), as quedas são um evento traumático, multifactorial e habitualmente involuntário e inesperado, acarretando consequências para o individuo, familiares, profissionais, instituições de saúde, assim como para a sociedade. Torna-se, portanto, fundamental sua correta caracterização, evidenciando suas especificidades. 
Sabia que...

A queda é a segunda causa de morte acidental ou não intencional no mundo?

Por ano, estima-se que 424 mil indivíduos falecem na sequência de uma queda?

Os adultos com idade superior aos 65 anos são os que mais sofrem quedas fatais (WHO 2012)?

A queda no paciente é o evento adverso mais reportado/notificado ao National Patient Safety Agency (NPSA) na Inglaterra e País de Gales?

Durante um ano, foram reportadas/notificadas ao NPSA mais de 200 mil quedas ocorridas em ambiente hospitalar?

Dessas 200 mil quedas reportadas/notificadas, 26 resultaram em morte, e, posteriormente, algumas fraturas da anca/fraturas de quadril tenham culminado da mesma forma em morte (NPSA 2007)?

\section{Como são classificadas as quedas?}

Os pacientes caiem por diversas razões, e, para que se implemente um efetivo plano preventivo, torna-se importante compreender sua etiologia. De acordo com Morse (2009), as quedas podem ser classificadas em:

\section{Quedas acidentais ou fisiológicas:}

associadas a perigos ambientais, como urina ou água derramada no chão, constituindo cerca de $14 \%$ do total de quedas;

\section{Quedas fisiologicamente previsíveis:}

correspondem aos indivíduos com elevada predisposiçăo para queda (alto risco), devido as suas inúmeras alteraçōes fisiológicas. Esse tipo de queda é responsável por $78 \%$ do total de quedas;

\section{Quedas fisiologicamente imprevisíveis:}

podem ser atribuídas a causas fisiológicas, no entanto, ocorrem sob condições que năo permitem a sua previabilidade, até a primeira ocorrência. Da totalidade de quedas ocorridas, $8 \%$ dizem respeito a esse tipo.

Essa classificação, como referido por Almeida, Abreu e Mendes (2010), remete-nos para a existência de factores que predispõem à ocorrência de queda, quer sejam factores intrínsecos, quer extrínseco. É sobre as causas de risco que nos debruçaremos de seguida. 
Para refletir

Você tem conhecimento da incidência de quedas no serviço, unidade ou na organização em que atualmente exerce funções? Você acredita que esses incidentes têm sido considerados (e valorizados), pela organização, um problema a que urge dar respostas? Por que você acredita ser dessa maneira?

\section{Quais as principais factores responsáveis pela ocorrência de queda?}

De forma a maximizar a efetividade da prevenção de quedas nos pacientes com elevado risco, torna-se premente identificar as causas que contribuem para esse incidente. Sabe-se que, na origem das quedas, estão múltiplos factores (causa multifactorial) e, por uma questão de sistematizar e agrupar esses factores, vários autores os classificam em dois grandes grupos: intrínsecos e extrínsecos (Ganz et al. 2013; Morse 2009; Nice 2013; NPSA 2007; Saraiva et al. 2008).

\section{Factores intrínsecos}

Os factores intrínsecos, também conhecidos por factores individuais, incluem alterações fisiológicas relacionadas com o avançar da idade, patologias e efeitos causados pelo uso de fármacos.

As alterações fisiológicas relacionadas com o próprio envelhecimento incluem alterações da visão e audição, distúrbios vestibulares, transformações ao nível dos reflexos posturais, flexibilidade, diminuição da capacidade funcional, deformidades ósseas, deformidades nos pés, distúrbios propriocetivos, diminuição da sensibilidade dos barorrecetores à hipotensão postural, sedentarismo, distúrbios musculoesqueléticos, marcha enfraquecida, aumento da incidência de condições patológicas.

No que se refere às patologias mais frequentes, predisponentes de quedas, é possível enumerar as doenças do foro cardíaco/doenças cardíacas, osteoarticulares, respiratórias, psiquiátricas, geniturinárias, endocrinometabólicas, neurológicas, demência, déficit cognitivo, e estado de saúde atual, como desidratação, hipoglicemia, déficit nutricional.

Ainda referente aos factores intrínsecos, o uso de fármacos é também apontado/indicado como um factor relevante para a ocorrência de queda. Dessa forma, múltiplos grupos de medicamentos são mencionados como responsáveis pelo aumento do risco de queda, como os 
diuréticos, hipotensores, vasodilatadores, nitratos, digitálicos, laxantes, opioides, hipoglicemiantes, hipnóticos, sedativos, ansiolíticos, analgésicos. A medicação múltipla, superior a quatro medicamentos por indivíduo, é igualmente referida como um factor importante no aumento do risco de queda.

\section{Factores extrínsecos}

Os factores externos referem-se aos perigos ambientais existentes nas unidades, em particular, e ao hospital, em geral. Infelizmente, as unidades hospitalares têm sido projetadas em função da necessidade dos funcionários, em detrimento da segurança do paciente.

Assim, as múltiplas áreas que contribuem para o aumento do risco incluem:

潘 corrimão: inexistência desses no quarto e casa de banho/banheiro e no percurso para eles;

pavimento: superfícies escorregadias, escadas, presença de cabos;

路 cama, cadeiras e dispositivos de apoio à marcha: inadequados, desajustados aos pacientes, sem grades, destravadas;

踏 campainha de chamada: fora do alcance do paciente;

suporte de soros: inapropriado em altura e mobilidade;

滕 iluminação: pouca luminosidade;

滕 vestuário: pouco apropriado;

滕 calçado: escorregadio;

蝶 mobiliário: design pouco apropriado a ambiente hospitalar.

\section{Para refletir}

Na organização em que você trabalha, em que condições estão as áreas que foram listadas anteriormente? Você já viu ou teve notícias de alguma queda em consequência de condições inapropriadas?

Para saber mais sobre as condições em que ocorrem as quedas, consulte o terceiro relatório do Observatório de Segurança do Paciente, da National Patient Safety Agency. Disponível em: http://www.nrls.npsa.nhs.uk/ resources/?entryid $45=59821$

Como já referido, os factores intrínsecos são os que mais contribuem para a ocorrência de queda; no entanto, a maioria das quedas é resultado de uma combinação de diferentes factores. Assim, é possível afirmar que as quedas são resultado da sinergia entre múltiplos factores, intrínsecos e extrínsecos. 
Sabia que...

Os pacientes sofrem mais quedas durante os dias úteis da semana, quando há mais pacientes no hospital.

É a meio da manhã que os pacientes sofrem mais quedas, por ser o momento em que se encontram mais ativos.

Apenas uma pequena porcentagem de quedas é testemunhada pelos profissionais de saúde.

Os pacientes idosos que já tenham sofrido um episódio de queda constituem um grupo vulnerável e de elevado risco para que o episódio se repita (NPSA 2007).

Paralelamente, o NPSA (2007) refere que os pacientes internados apresentam um risco acrescido de queda em comparação com os residentes na comunidade, e isso ocorre por causa de sua condição de saúde no momento, à medicação, que pode condicionar sua mobilidade, e/ou à memória, assim como pela presença de um ambiente que lhe é estranho.

\section{Quais as principais consequências quando ocorre uma queda?}

As consequências decorrentes de uma queda podem ser divididas em três grandes grupos: físicas, psicológicas e sociais (Oliver et al. 2004; NPSA 2007; NHS 2009), como demonstra o quadro a seguir.

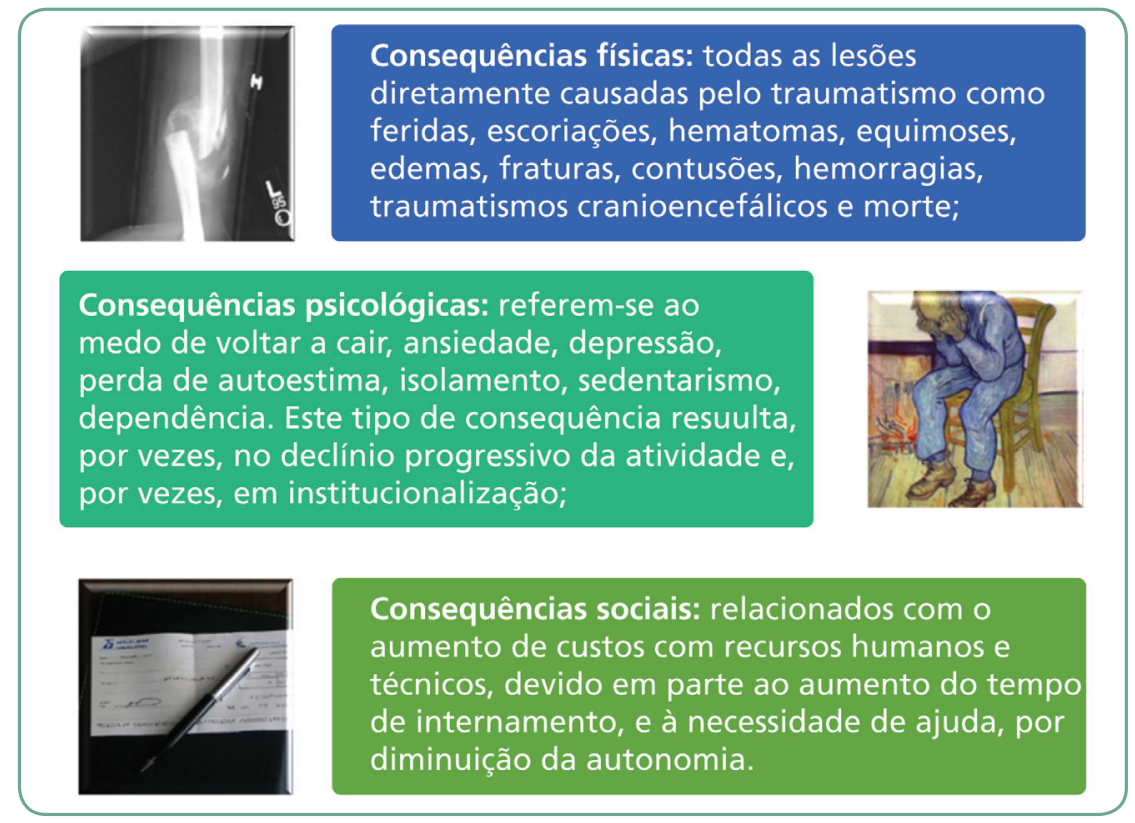

Fonte: Rhodes (2004), The Yorck Project (2005), Pshegubj (2010). 
Sabia que...

Num estudo realizado por Schwendimann et al. (2006), 66.4\% das quedas ocorridas num hospital público de Zurich não resultaram em danos físicos, $29.7 \%$ resultaram em danos físicos reduzidos, e $3.9 \%$ das quedas ocorridas provocaram lesões físicas severas.

Por fim, de acordo com NPSA (2007), é possível referir que, para além dos custos humanos, existem ainda outros custos relacionados com aumento de recursos materiais e profissionais, demora média de internamento/internação estimados em 15 milhões de libras a cada ano. Todavia, existem custos adicionais difíceis de quantificar, por exemplo, um paciente que sofra uma queda e, após alta hospitalar, necessite de cuidados continuados, como se verifica a título exemplificativo, com pequenas feridas que degeneram para úlceras e necessitam de tratamento prolongado, e esses custos não estão incluídos nesse valor. O mesmo se constata com custos envolvidos com as reclamações e indenizações. Mais recentemente, um estudo da OCDE (Slawomirski et al. 2017) veio destacar o impacto económico dos eventos adversos em geral e, das quedas em particular.

As consequências de uma queda não são apenas vividas pelo paciente, mas também pelos seus familiares, cuidadores e pelos profissionais de saúde, causando, por vezes, neles sentimento de culpabilidade e ansiedade (Oliver et al. 2004).

A gravidade do incidente pode ser ainda classificada em diferentes graus, que, segundo o NPSA (2007), é possível classificar da seguinte forma:

* Sem lesão ou prejuízo: quando não ocorreu qualquer dano físico para o paciente.

Hesão leve: quando resulta em dano ou ferimento que requer primeiros socorros, tratamento minor, observação ou medicação extra.

橉 Lesão moderada: quando resulta em tratamento em ambulatório, algum tipo de cirurgia, ou internamento/internação prolongado no hospital.

蝶 Lesão severa: quando causa lesão permanente, como dano cerebral, resultando em diferentes incapacidades.

Morte: quando a morte é causa direta da queda. 
Sabia que...

Intervenções multidimensionais (alinhadas) podem reduzir o risco de queda em até 30\% (Miake-Lye et al. 2013).

\section{É possível prevenir quedas?}

A intervenção no sentido de prevenir a ocorrência de quedas deve envolver os diferentes profissionais de saúde, familiares e o próprio paciente. E porque cada paciente é único, seu plano preventivo deve ser individualizado, de acordo com suas necessidades, traduzindo um equilíbrio entre as ações preventivas e sua independência, privacidade, dignidade e reabilitação (NPSA 2007; Ganz et al. 2013).

A prevenção deve iniciar-se com a avaliação do paciente e dos seus factores de risco, e existem diversos instrumentos possíveis para avaliar o risco de queda. No entanto, a Escala de Morse, como é referida por McFarlane-Kolb (2004), é facilmente adaptável a diferentes contextos. Talvez, por esse facto, seja mais comumente utilizada um pouco por todo o mundo.

De acordo com Ganz et al. (2013), a aplicação dessa escala (Morse) deve ser efetuada quando da admissão do paciente ao serviço de internamento/internação; na sua transferência para outra unidade ou serviço; quando ocorre alguma alteração na condição do paciente; ou após um episódio de queda.

A Escala de Morse é composta de seis parâmetros de avaliação listados a seguir:

1. história de queda;

2. diagnóstico secundário;

3. apoio para se deslocar/caminhar;

4. medicação endovenosa/cateter heparinizado;

5. marcha, e

6. estado mental.

Cada um dos parâmetros corresponde a um valor numérico, que somado entre todos confere um score, perante o qual é atribuído o risco (veja na Tabela 1). Quando o valor é inferior a 25, o paciente apresenta baixo risco de queda. Quando o valor se encontra entre o 25 e 45, o paciente apresenta risco moderado de queda. Por fim, se o valor obtido na avaliação for superior a 45, o paciente apresentará alto risco 
de queda, devendo assim a intervenção incidir num plano preventivo personalizado que engloba diferentes ações, de acordo com os diferentes factores de risco do paciente (Quadro 1).

Tabela 1 - Itens de avaliação da Escala de Morse

\begin{tabular}{|c|c|c|}
\hline Item & $\begin{array}{l}\text { Pontuação } \\
\text { da escala }\end{array}$ & $\begin{array}{l}\text { Pontuação } \\
\text { do paciente }\end{array}$ \\
\hline História de queda (imediata ou anterior) & $\begin{array}{ll}\text { Não } & 0 \\
\text { Sim } & 25\end{array}$ & \\
\hline Diagnóstico secundário & $\begin{array}{ll}\text { Não } & 0 \\
\text { Sim } & 15\end{array}$ & \\
\hline $\begin{array}{l}\text { Apoio para se deslocar/caminhar } \\
\text { - Nenhuma/acamado/apoio do enfermeiro } \\
\text { - Muletas/canadianas/andarilho } \\
\text { - Apoia-se no mobiliário }\end{array}$ & $\begin{array}{l}0 \\
15 \\
30\end{array}$ & \\
\hline - Medicação endovenosa/cateter heparinizado & $\begin{array}{l}\text { Não } \\
\text { Sim }\end{array}$ & \\
\hline $\begin{array}{l}\text { Marcha } \\
\text { - Normal/acamado/cadeira de rodas } \\
\text { - Enfraquecida } \\
\text { - Necessita de apoio }\end{array}$ & $\begin{array}{c}0 \\
10 \\
20\end{array}$ & \\
\hline $\begin{array}{l}\text { Estado mental } \\
\text { - Consciente das suas capacidades } \\
\text { - Superestima/esquece-se das suas limitações }\end{array}$ & $\begin{array}{c}0 \\
15\end{array}$ & \\
\hline $\begin{array}{l}\text { Total da pontuação } \\
<25 \text { Baixo Risco } \\
\text { 25-45 Risco Moderado } \\
>45 \text { Alto Risco }\end{array}$ & & TOTAL \\
\hline
\end{tabular}

Fonte: Adaptado de Morse (2009).

Quadro 1 - Intervenções que devem ser realizadas em pacientes que apresentam alto risco de queda

\section{Intervenções ao nível dos factores intrínsecos}

- Envolver os pacientes e os familiares na prevenção das quedas, alertando para os factores de risco.

- Detetar e tratar doença cardiovascular.

- Detetar e tratar as causas de delírio.

- Detetar e tratar problemas de visão. 
Quadro 1 - Intervenções que devem ser realizadas em pacientes que apresentam alto risco de queda (cont.)

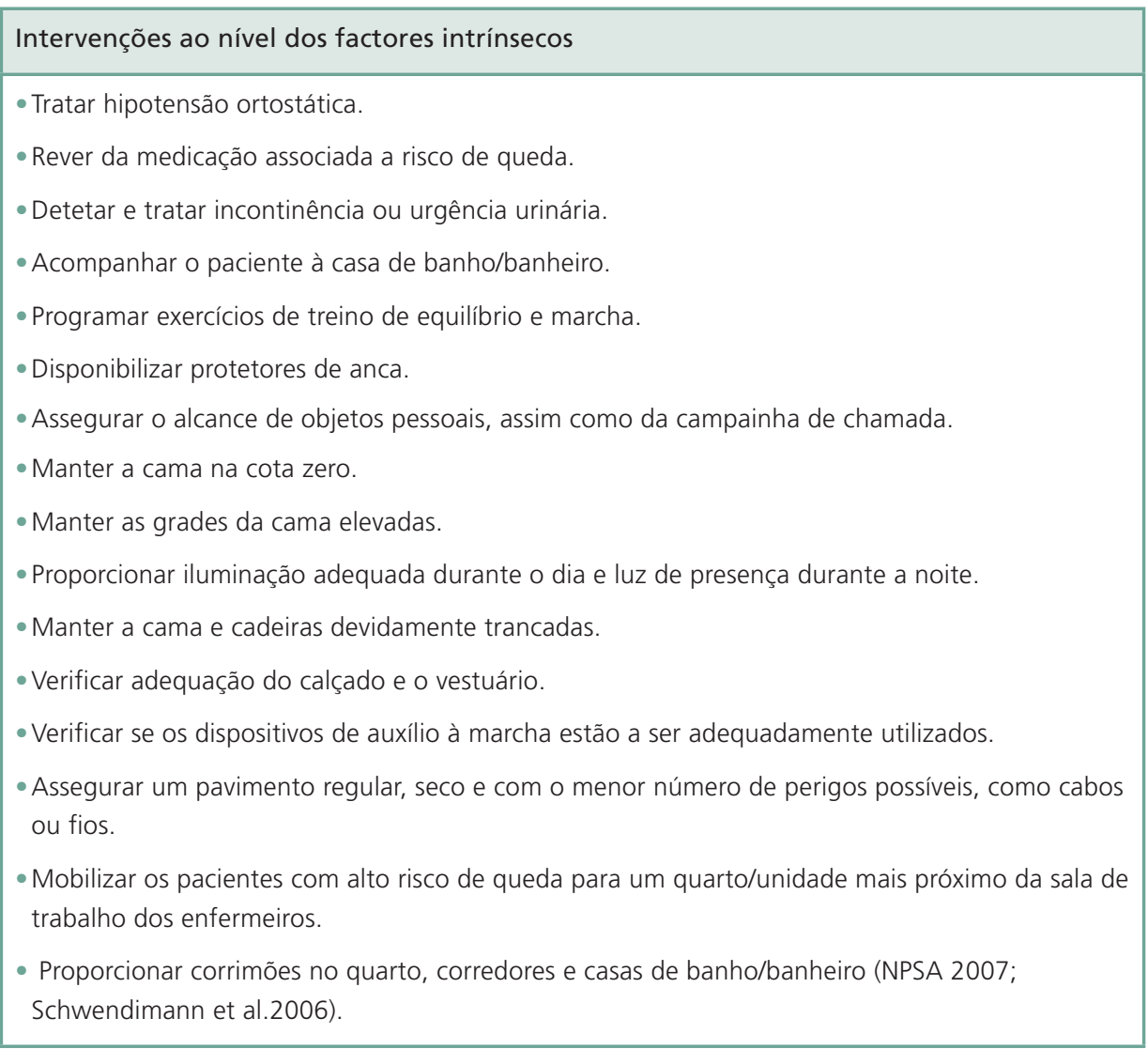

Fonte: Ganz et al. 2013; NPSA 2007; Schwendimann et al. 2006.

Contudo, a prevenção de quedas pode não se restringir unicamente à avaliação do risco de queda (aplicação de uma escala) e à intervenção nos factores de risco. As estratégias de prevenção podem ser complementadas com uma cultura de constante investigação das situações de quedas; criação de um grupo de "quedas"; eleição de um profissional (enfermeiro, médico) dinamizador; treino dos profissionais de saúde para implementar as medidas preventivas; realização de auditorias e; aprendizagem por meio da análise das circunstâncias em que ocorreram as quedas, conforme esquematizado na Figura 1 (Almeida, Abreu, Mendes 2010; NHS 2009).

\section{1.}

Para saber mais sobre as medidas preventivas, recomendamos a consulta dos seguintes sites:

- http://www.npsa.nhs.uk/

- http://www.patientsafetyfirst. nhs.uk/

- http://www.nice.org.uk/ No Brasil, existe um protocolo de prevenção de quedas:

- http://www.anvisa.gov.br/ hotsite/segurancadopaciente/ documentos/julho/

Protocolo\%20-\%20

Preven $\%$ C $3 \% \mathrm{~A} 7 \%$

C3\%A30\%20de

\%20Quedas.pdf 
Figura 1 - Estratégias de prevenção de quedas baseadas na evidência científica

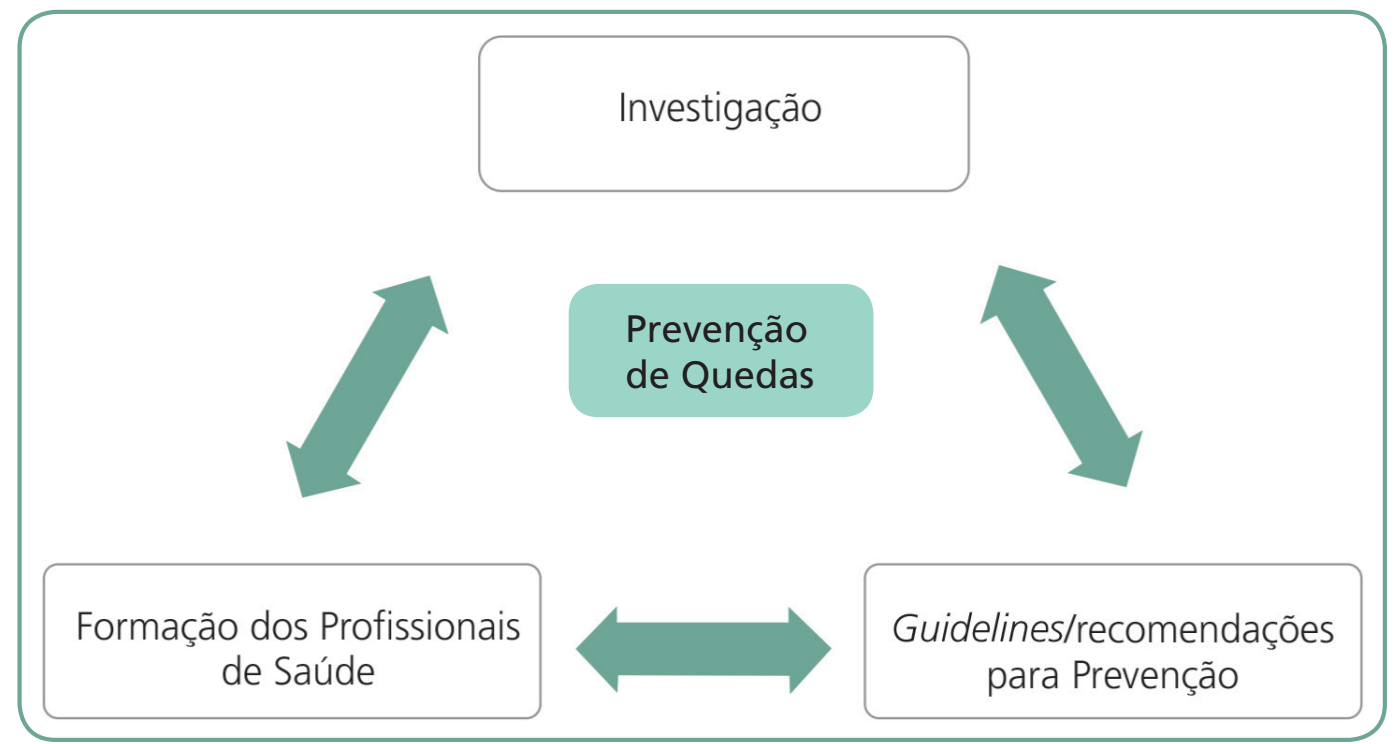

Fonte: Adaptado de Almeida, Abreu, Mendes (2010).

\section{Para refletir}

Na sua organização, é prática atual a avaliação do risco de quedas para todos os pacientes? Considera isso importante? Por quê?

Ainda na sua organização, existem estratégias de prevenção para quedas das que foram discutidas até aqui? (procedimentos normalizados, instrumentos de avaliação do risco, grupo de trabalho, elemento dinamizador).

\section{O que fazer quando ocorre uma queda?}

Quando ocorre uma queda, deve-se de imediato avaliar o paciente, identificar e caracterizar as lesões e tratá-las com a maior brevidade possível. Adicionalmente, devem ser identificadas as causas intrínsecas e extrínsecas que levaram à queda. Em paralelo, os profissionais devem eliminar, tanto quanto possível, os riscos que contribuíram para que a queda ocorresse. Por fim, mas não menos importante, os profissionais de saúde devem relatar o incidente mencionando a informação-chave (tão clara e descritiva quanto possível), promovendo assim o conhecimento da presença dos factores de risco e a aprendizagem por meio dessas ocorrências (NHS 2009; NPSA 2007; Oliver et al. 2004). 


\section{Úlceras por pressão}

O National Pressure Ulcer Advisory Panel e o European Pressure Ulcer Advisory Panel definem úlcera por pressão (UP) como uma “lesão causada na pele ou no tecido subjacente, geralmente sob uma proeminência óssea, como resultado da pressão ou da combinação entre a pressão e as forças de torção" (EPUAP 2009, p.7).

Uma úlcera por pressão pode apresentar quatro categorias que variam de acordo com os tipos de tecidos atingidos:

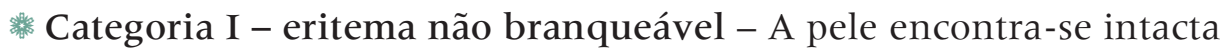
e ruborizada; ao toque, não branqueia. A área pode encontrar-se dolorosa, firme, suave, mais quente ou mais fria comparativamente com o tecido adjacente. Segundo O National Pressure Ulcer Advisory Panel e o European Pressure Ulcer Advisory Panel, essa categoria pode ser difícil de detetar em indivíduos que apresentem tons de pele mais escuros.

Figura 2 - Úlcera por pressão: categoria I

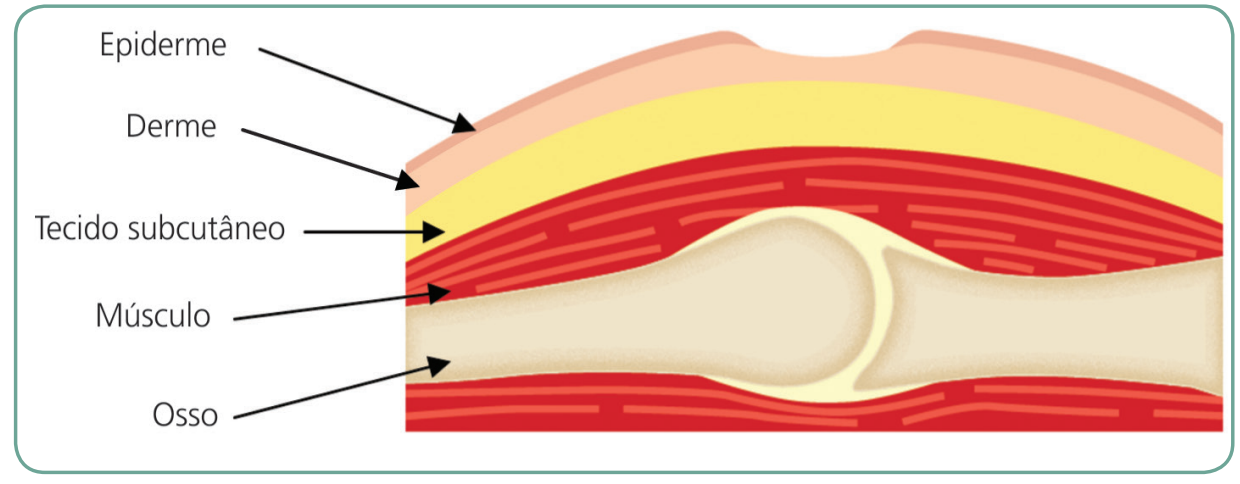

Ilustração de Armando Lopes.

Categoria II - perda parcial da espessura da pele Observa-se uma lesão aberta pouco profunda. Também se pode apresentar como uma flictena (empolamento da epiderme, tipo "bolha"); é uma úlcera superficial brilhante ou seca sem esfacelo ou hematomas. 
Figura 3 - Úlcera por pressão: categoria II

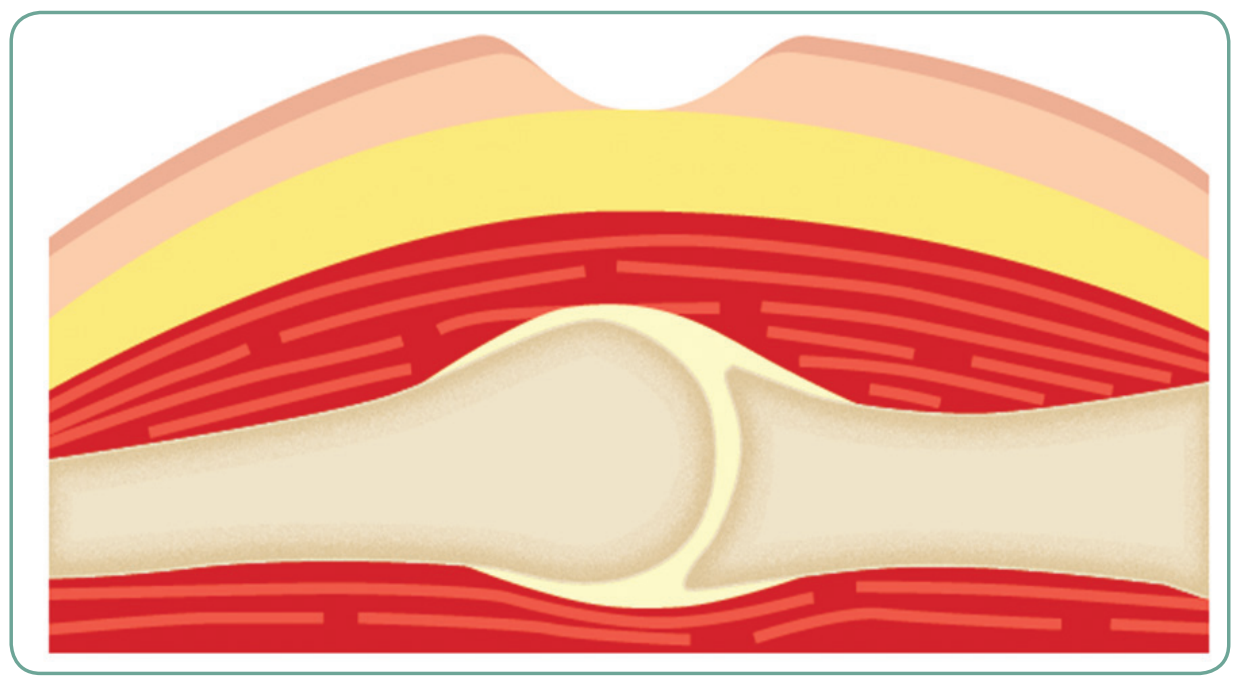

Ilustração de Armando Lopes.

* Categoria III - perda total da espessura da pele - O tecido subcutâneo encontra-se visível; os ossos, tendões ou músculos não se encontram expostos. Nessa categoria, incluem-se as úlceras tunelizadas. A profundidade de uma úlcera por pressão III varia consoante a localização anatómica. Uma vez que a asa do nariz, os pavilhões auriculares, a região occipital e maleolar não apresentam tecido adiposo subcutâneo, as úlceras II, nessas localizações, podem ser pouco profundas. No entanto, as regiões anatómicas com adiposidade significativa podem desenvolver úlceras por pressão extremamente profundas.

Figura 4 - Úlcera por pressão: categoria III

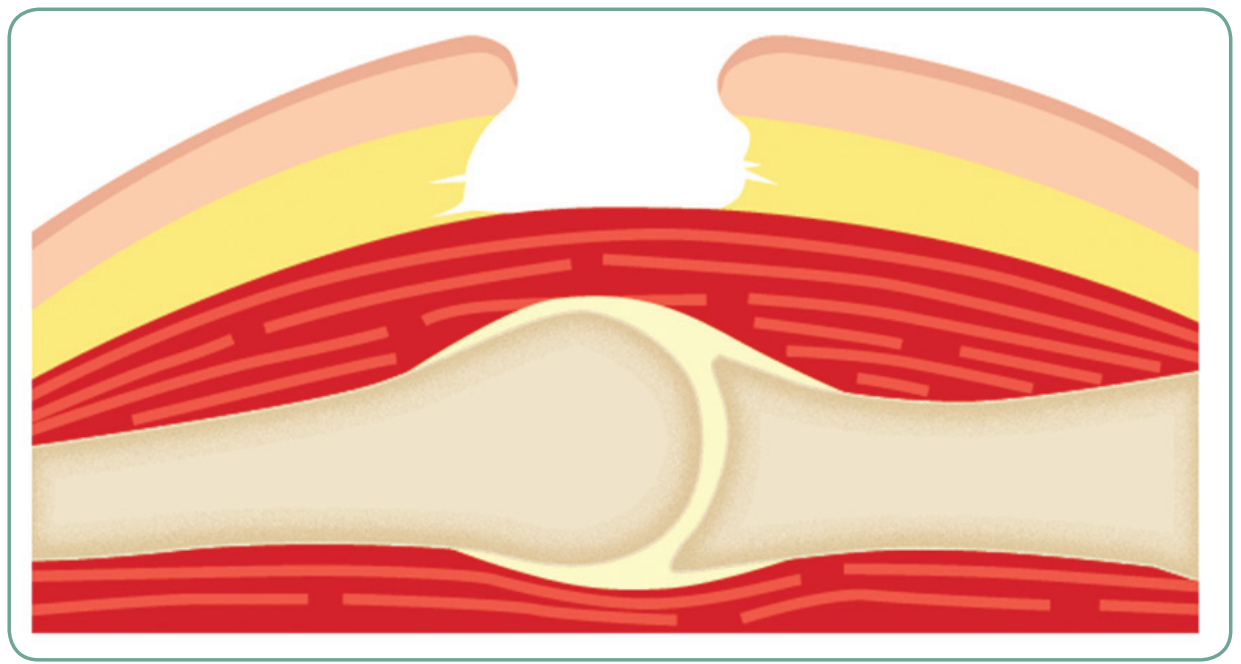

Ilustração de Armando Lopes. 
Categoria IV - perda total da espessura tecidular - Verifica-se exposição do osso, tendão ou músculo; podem estar presentes tunelizações. À semelhança da categoria III, também na IV, a profundidade varia de acordo com a localização anatómica. A asa do nariz, os pavilhões auriculares e as regiões occipital e maleolar não têm tecido adiposo subcutâneo, e as úlceras, nessas localizações, podem ser pouco profundas. As úlceras dessa categoria podem ser causa de osteomielite ou osteíte; o músculo e/ou osso encontram-se visíveis ou diretamente palpáveis.

Figura 5 - Úlcera por pressão: categoria IV

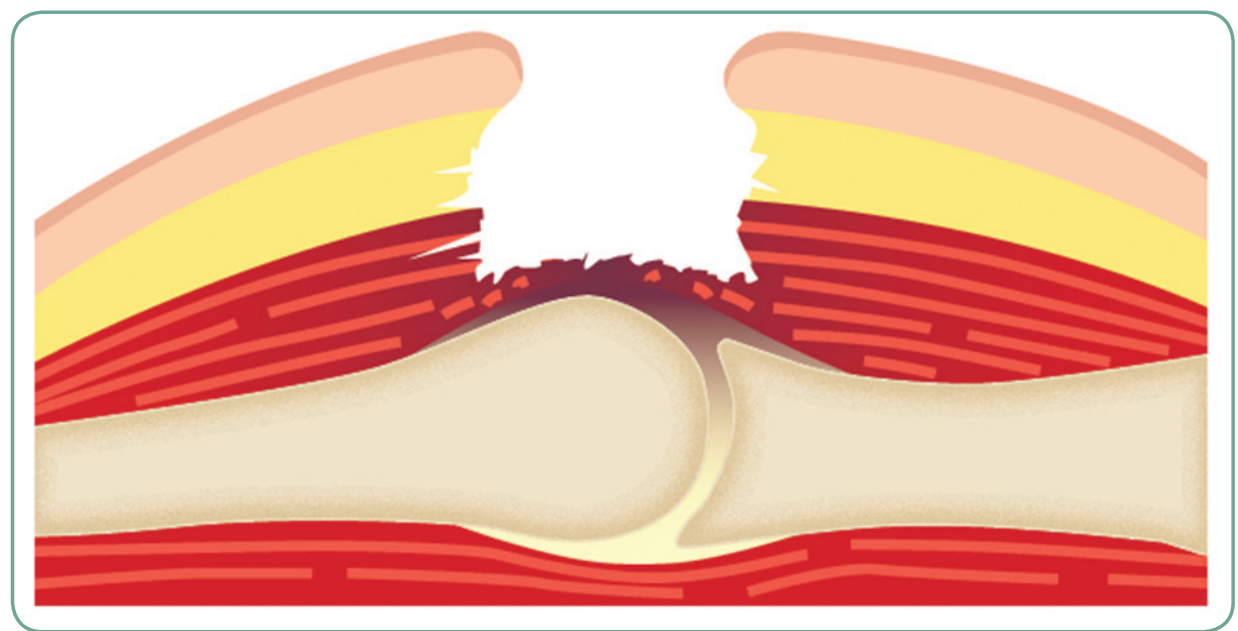

Ilustração de Armando Lopes.

Nos Estados Unidos da América, ainda são definidas duas outras categorias adicionais (EPUAP 2009):

* perda total da espessura da pele e tecidos com profundidade desconhecida;

suspeita de lesão dos tecidos profundos com profundidade desconhecida.

\section{Importância da avaliação do risco de UP}

Existem diversas escalas de avaliação do risco de úlceras por pressão, tais como Braden, Norton, Waterloo, que diferem, entre outros, nos parâmetros a avaliar.

Em Portugal, a escala adotada e validada é, desde 2001, a de Braden (veja a escala a seguir) na qual são avaliados seis parâmetros: perceção sensorial, humidade, atividade, mobilidade, nutrição e fricção de deslizamento.

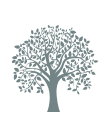

No Brasil, existe um protocolo que tem por objetivo a prevenção de úlcera por pressão, desenvolvido em parceria entre o Ministério da Saúde, a Anvisa e a Fiocruz. Disponível em: http://www.anvisa.gov.br/ hotsite/segurancadopaciente/ documentos/julho/ PROTOCOLO $\% 20$ ULCERA $\% 20$ POR\%2OPRESS\%C3\%830.pdf 
Em cada parâmetro da Escala de Braden, o enfermeiro deve, perante o paciente a avaliar, selecionar uma situação entre as três ou quatro enunciadas (para cada parâmetro). A cada situação selecionada corresponde uma determinada ponderação numérica, e, posteriormente, soma-se o conjunto dos valores obtidos em cada parâmetro avaliado.

Quanto mais baixa for a pontuação obtida, maior será o risco de o paciente vir a desenvolver úlceras por pressão. Quando a soma dos seis parâmetros avaliados resulta em um valor igual ou inferior a 16, o resultado sugere que o paciente apresenta risco elevado para o desenvolvimento de úlceras por pressão. Caso o resultado obtido seja superior ou igual a 17, constata-se que existe baixo risco de desenvolvimento de úlceras por pressão.

Mediante os resultados obtidos com a utilização da Escala de Braden (ou outra validada), existe a possibilidade de elaborar planos de cuidados adequados às necessidades dos pacientes.

\section{Para refletir}

Em sua organização, usa-se algum tipo de escala ou protocolo para prevenção de úlcera por pressão? Qual? Você acredita que essa prática tem trazido bons resultados? 


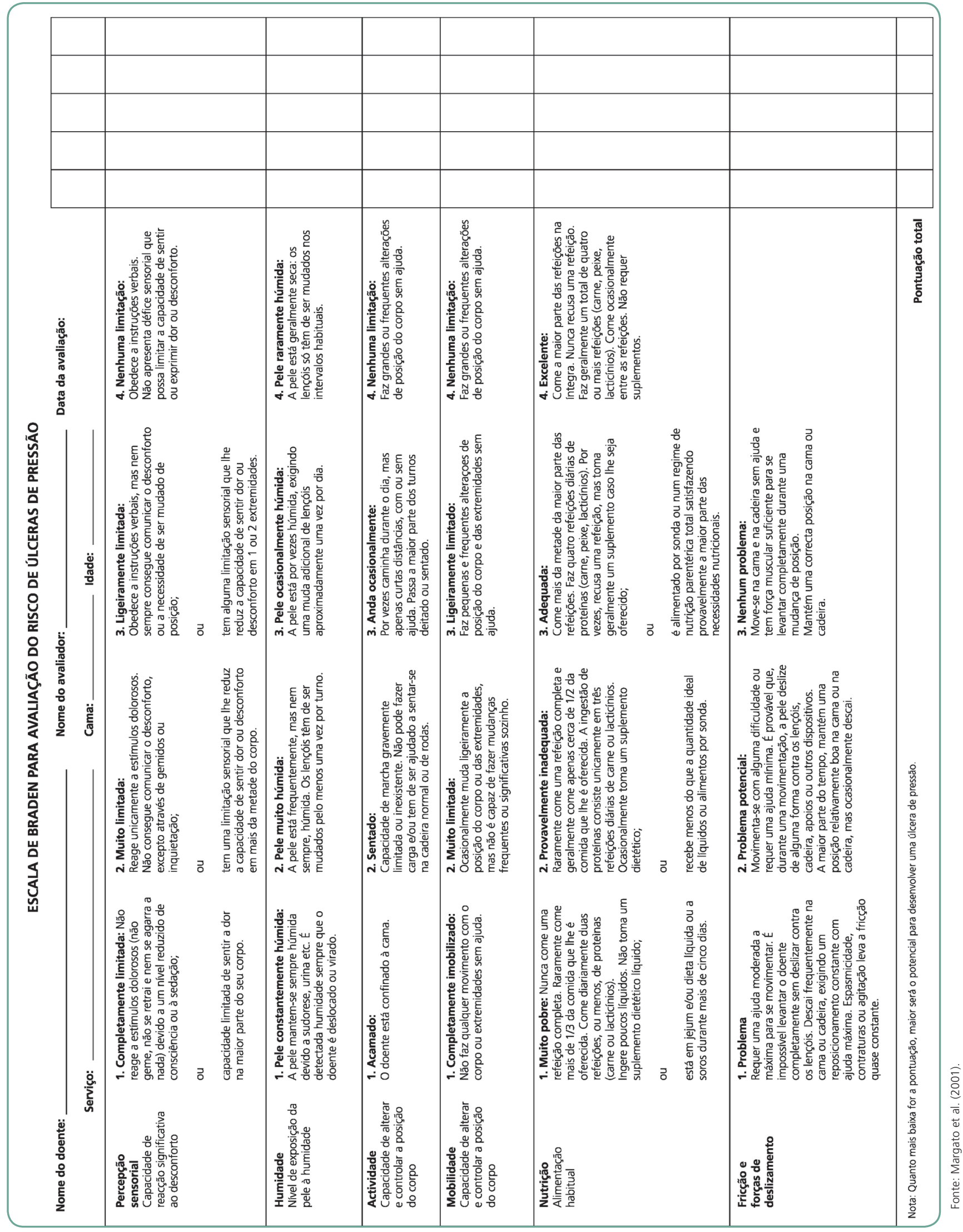


O suporte fotográfico pode funcionar como adjuvante/ colaborador na prática da avaliação do risco de úlceras por pressão. É prática frequente dos profissionais de enfermagem e pessoal médico procederem ao registo fotográfico das úlceras por pressão e posterior inclusão no processo clínico/prontuário, para que se consiga comparar, visualmente, a evolução obtida.
A avaliação do risco deve ser efetuada no dia da admissão, possibilitando assim a comparabilidade e a contínua atenção por parte dos profissionais acerca da evolução observada e da necessidade de manter o plano de cuidados elaborado para o paciente, ou de o alterar consoante a sua evolução.

Em Portugal, a Direção-Geral da Saúde elaborou uma orientação (Ministério da Saúde 2011) na qual se defende a periodicidade de reavaliação, por parte dos enfermeiros, do risco de desenvolvimento de úlceras por pressão. Assim:

- Internamentos/internações hospitalares - de 48/48 horas a todos os pacientes internados.

- Serviços de urgência e unidades de cuidados intensivos - de 24/24 horas.

- Unidades de cuidados continuados e paliativos - de 48/48 horas.

- Cuidados domiciliários - semanalmente.

- Pacientes que não permaneçam mais de 48 horas num serviço de internamento/internação - efetuar avaliação caso ocorra alguma intercorrência.

Para saber mais sobre essas orientações consulte, a página da DGS em: http://www.dgs.pt/upload/membro.id/ficheiros/i015800.pdf

A monitorização contínua da incidência e da prevalência das úlceras por pressão é fundamental, pois é preciso

testar se as ferramentas reduzem a ocorrência de eventos adversos, e não assumir que uma ferramenta validada será benéfica para os pacientes. Apesar das evidências de que preveem o risco, não há evidência de que as ferramentas de avaliação do risco reduzam a incidência de úlceras por pressão (Anthony et al. 2010, p.135).

\section{A dor no paciente com UP}

Quando se aborda o tema das úlceras por pressão, outro tópico surge, imediatamente, lado a lado com ele - a dor; dor pela existência da úlcera, pelos apósitos/curativos utilizados, pela manipulação da ferida, entre outros factores. Para Pieper, Langemo e Cuddigan (2009), a dor é encarada como uma experiência sensorial e emocional desagradável, associada a um dano tecidual real ou potencial.

Independentemente da idade do paciente ou de seu estado de saúde, a existência de dor não pode ser subvalorizada, pois sua presença contém 
implicações psicossociais quer para o paciente, quer para a família ou, ainda, para os profissionais de saúde.

De acordo com os autores supracitados, a World Union Of Wound Healing Societies elaborou um documento que define os princípios de boas práticas associadas à manipulação das úlceras por pressão, nas quais se considera importante:

繗 estar ciente da dor provocada pela existência de ferida;

轔 evitar manipulações desnecessárias;

诌 explorar técnicas para minimizar a dor;

喝 avaliar a pele e o tecido circundante em termos de presença de infeção ou necrose;

atender à temperatura dos apósitos/curativos utilizados;

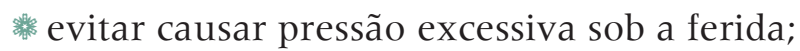

繙 fornecer avaliação e monitorização contínua.

\section{As úlceras por pressão são evitáveis?}

Cerca de 95\% das úlceras por pressão podem ser evitadas se existir a identificação precoce do grau do risco (Ministério da Saúde 2011; Posnett, Franks 2008).

No Reino Unido, Posnett e Franks (2008) concluíram que cerca de 400 mil pessoas desenvolviam, anualmente, uma nova úlcera por pressão. Isso podia ser, em certos casos, evitado com consequente redução não só das complicações e comorbilidades/comorbidades associadas, como também das despesas em saúde.

Em Portugal, a prevalência das úlceras por pressão em meio hospitalar varia entre 11,5\% para a prevalência média e 17,5\% quando estratificado para serviços específicos, tais como os serviços de medicina (Ministério da Saúde 2011).

\section{Será que a ocorrência de úlceras por pressão é evitável em todas as situações?}

Essa foi uma das questões em análise numa conferência efetuada em 2010 pelo National Pressure Ulcer Advisory Panel, na qual, entre outros aspetos, os peritos de diversas organizações prestigiadas concluíram que "nem todas as úlceras por pressão são evitáveis, porque existem 
Courtney et al., citados por Sullivan e Schoelles (2013), verificaram que uma redução de $50 \%$ para $5 \%$ de úlceras por pressão adquiridas em meio intra-hospitalar representou diminuição das despesas em $\$ 2.438 .000$ US dólares, e, em 2008, num hospital da Flórida com 548 camas/leitos a redução, estatisticamente significativa, da prevalência de UP acarretou a poupança de $\$ 11.5$ milhões de US dólares. situações em que a pressão do paciente não pode ser aliviada, e a perfusão não pode ser melhorada" (Black et al. 2011, p.30). Entre outras conclusões, os autores consideraram que:

\section{Situações limitantes à evitabilidade do surgimento das UP}

A mobilidade e as limitações de atividade são fortes e independentes fatores contribuem para a incidência das úlceras por pressão.

Embora não se tenha concluído até a data acerca do correto intervalo que determine a alternância de posicionamentos, 0 intervalo de duas em duas horas continua a ser utilizado como guia orientador.

Não importa o quão adequado e correto é o plano de cuidados desenhado para um paciente e o quão sofisticado é a cama/leito e colchão que este utiliza, se nao existirem profissionais disponíveis, com boa formaçăo e competentes para colocar em prática.

\section{Os custos das UP... Prevenir ou tratar?}

A estratégia de abordagem nas úlceras por pressão deverá ser multifactorial, pois sua existência e complicações acarretam custos elevados. Segundo Sullivan e Schoelles (2013), nos Estados Unidos da América, as complicações associadas às UP adquiridas em meio intra-hospitalar causam, por ano, cerca de 60 mil mortes e morbilidades/morbidades em um número significativo de pacientes. Embora se tenha anteriormente mencionado que nem todas as úlceras por pressão são evitáveis, a aposta na sua prevenção é essencial não só para proteger os pacientes, como também para reduzir os custos económicos e sociais associados.

Um estudo desenvolvido por Bennett, Dealey e Posnett (2004) no Reino Unido concluiu que:

- O custo esperado de cura de uma úlcera por pressão varia de acordo com a sua categoria - 1.064 Libras (UPP categoria I) a 10.551 (UPP categoria IV).

- "O custo aumenta com a categoria da úlcera, porque o tempo necessário para a cura é mais longo para uma úlcera mais grave, assim como a possibilidade de incidência de complicações" (Bennett et al. 2004, p.233).

- Os cuidados aos pacientes com úlceras por pressão foi estimado em cerca de $4 \%$ do total das despesas do Serviço Nacional de Saúde inglês (NHS) - O custo total dos cuidados relacionados com úlceras por pressão no Reino Unido varia entre 1.4 a 2.1 mil milhões/bilhões de libras. 
Dealey, Posnett e Walker (2012) concluíram, mediante um estudo realizado no Reino Unido, que os custos relativos ao tratamento diário de pacientes com UP categorias I e II variam entre 43 e 347 libras. Os autores concluem que uma UP categoria I pode custar mais de mil libras por episódio de internamento/internação. Por isso, é fundamental ter consciência da possibilidade de ocorrência de complicações (tais como infeção, celulite ou osteomielite) com consequente aumento do tempo de internamento/ internação, atraso da cura e aumento dos custos - daí a contínua importância do investimento na prevenção e no tratamento precoce.

Os custos elevados que a existência de úlceras por pressão origina servem também de alavanca para otimizar os cuidados e modernizar as práticas. Um estudo desenvolvido por McGuinness et al. (2012) num serviço de neurociência (neurologia e neurocirurgia) de um hospital nos Estados Unidos da América implementou, desde 2008, uma estratégia de cuidados que envolvia, entre outras ações:

a aquisição de camas específicas;

* uma cultura de alternância de decúbitos dos pacientes de uma em uma hora ou de duas em duas horas;

橉 a criação de uma equipa especializada denominada Skin and Wound Assessment Team (SWAT), constituída de enfermeiros especializados na área que monitorizavam a existência de úlceras por pressão.

\section{Para refletir}

Na organização em que você desempenha funções, existe um grupo de profissionais (tipo grupo de avaliação ou prevenção de úlceras por pressão) que se dedica às questões das úlceras por pressão?

Caso exista, ele tem obtido sucesso? Caso não exista, a que se deve essa ausência? 
Implementar medidas de avaliação, gestão e prevenção das úlceras por pressão permite obter ganhos ao nível da qualidade dos cuidados e da segurança do paciente.
Os autores mencionam que, mediante as estratégias adotadas, assistiram a uma importante redução da incidência de úlceras por pressão adquiridas em meio hospitalar, no referido serviço, de $48 \%$ em 2009, de $57 \%$ em 2010 e de $61 \%$ em 2011 , e consequente redução dos custos por internamento/internação (um paciente com úlcera de pressão categoria IV custa em média, segundo os autores, 129.248 dólares americanos, por um único internamento/internação/admissão) (McGuinness et al. 2012).

Num outro estudo, Brem et al. (2010) referem que cerca de 50\% de úlceras por pressão categoria II e $95 \%$ de úlceras por pressão categorias III e IV não cicatrizaram em oito semanas. Os autores mencionam que a presença ou o desenvolvimento de uma úlcera por pressão pode aumentar o tempo de internamento/internação, em média, em 10,8 dias.

\section{Para praticar}

- Qual a importância do contínuo investimento em práticas de avaliação e gestão do risco de UP?

- A existência de equipas especializadas e multidisciplinares, nas Organizações de Saúde, trará benefícios em termos de diminuição da frequência e/ou gravidade das úlceras por pressão?

\section{Incidentes relacionados com a transfusão de sangue e hemoderivados}

A medicina transfusional é a área médica que se refere à utilização terapêutica do sangue e componentes sanguíneos, incluindo a transfusão sanguínea. A transfusão de sangue consiste na perfusão de um determinado volume de sangue ou componente sanguíneo, proveniente de um dador/doador saudável, a um paciente.

A transfusão sanguínea é uma parte essencial da moderna assistência à saúde, podendo ter desde funções profilácticas a terapêuticas. O uso clínico dos diferentes componentes sanguíneos são variáveis, e vão desde o tratamento de anemias até à prevenção de hemorragias (Quadro 2). 
Quadro 2 - Uso clínico dos componentes sanguíneos

\begin{tabular}{|c|c|c|}
\hline Eritrócitos & Plaquetas & Plasma \\
\hline $\begin{array}{l}\text { - Traumas } \\
\text { - Cirurgias } \\
\text { - Anemias severas }\end{array}$ & $\begin{array}{l}\text { - Prevenção de hemorragias } \\
\text { - Correção de problemas de } \\
\text { funcionalidade das plaquetas }\end{array}$ & $\begin{array}{l}\text { - Correção de deficiências de } \\
\text { fatores de coagulação } \\
\text { - Hemorragias massivas }\end{array}$ \\
\hline
\end{tabular}

Fonte: Fonte: Adaptado de Chaudhary (2011)

Por exemplo, a transfusão de eritrócitos é utilizada em diversas áreas clínicas, quer para prevenção quer para tratamento (Figura 6).

Figura 6 - Estimativa da transfusão de eritrócitos nos países desenvolvidos

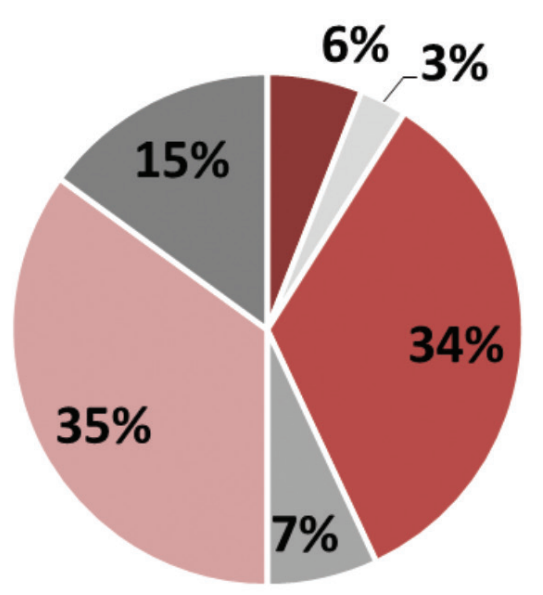

- Relacionado com a gravidez

Pediátricas

- Cirúrgicas

- Traumas

Médicas

Hematológicas

Fonte: Adaptado de WHO (2006).

A transfusão de componentes sanguíneos e seus derivados, se usada corretamente, pode salvar vidas e melhorar a saúde dos pacientes. No entanto, à semelhança das demais práticas médicas, não é isenta de riscos. E embora seja uma prática conhecida desde tempos remotos, sempre foi acompanhada por barreiras à sua aplicação em virtude das questões essenciais de segurança que se iam colocando.

Em tempos passados, os riscos associados à transfusão estavam relacionados com a transmissão de agentes infecciosos (Figura 7) e incompatibilidades sanguíneas por desconhecimento dos diferentes sistemas de grupos sanguíneos. No entanto, com os constantes avanços científicos, essas preocupações foram sendo colmatadas/atenuadas, e, atualmente, o risco de uma ocorrência desse gênero é apenas residual. 
Figura 7 - Risco de transmissão de infeção através da transfusão nos EUA, por unidade transfundida

\begin{tabular}{|l|c|c|}
\cline { 2 - 3 } \multicolumn{1}{c|}{} & $\mathbf{1 9 8 5}$ & $\mathbf{2 0 0 7}$ \\
\hline HIV & $1 / 100000$ & $1 / 1000000$ \\
\hline HBV & $1 / 1000$ & $1 / 80000$ \\
\hline HCV & $1 / 100$ & $1 / 800000$ \\
\hline Bactérias & $1 / 3000$ & $1 / 80000$ \\
\hline $\begin{array}{l}\text { Agentes } \\
\text { Emergentes }\end{array}$ & & $1 / 30000$ \\
\hline
\end{tabular}

Fonte: Adapatdo de Klein et al (2007).

$\mathrm{O}$ risco de transmissão de Hepatite $\mathrm{B}$ e $\mathrm{C}$ e HIV tem vindo a diminuir significativamente ao longo dos anos. Também o risco de transmissão de infeções bacterianas, associado à transfusão de plaquetas, diminuiu na última década. Os constantes avanços tecnológicos permitiram não só obter testes de rastreio cada vez mais sensíveis e específicos, detetando os agentes infeciosos mais precocemente, mas também criar tecnologias que reduzem a transmissão de um vasto leque de agentes infeciosos. A implementação de critérios mais apertados na seleção de dadores de sangue também foi uma medida tomada nesse sentido.

Apesar das melhorias significativas da segurança dos componentes sanguíneos, os erros de transfusão e as reações adversas daí decorrentes ainda ocorrem um pouco por todo o mundo. Embora algumas complicações relacionadas com a transfusão sejam inevitáveis, a maioria das reações transfusionais fatais é atribuída ao erro ou falha humano. Esses erros ou falhas podem conduzir a diferentes impactes nos pacientes (podendo mesmo levar à morte) e, consequentemente, a maior necessidade de alocação de recursos.

Os riscos transfusionais (Quadro 3) podem resultar em complicações fisiológicas que podem colocar em risco a vida dos pacientes. É possível que as complicações tenham origem em erros decorrentes de procedimentos inadequados e incorretos ao longo do processo transfusional, ou podem ter por base outras situações alheias a esse processo.

Os riscos transfusionais (Quadro 3) podem resultar em complicações fisiológicas que podem colocar em risco a vida dos pacientes. É possível que as complicações tenham origem em erros decorrentes de procedimentos inadequados e incorretos ao longo do processo transfusional, ou podem ter por base outras situações alheias a esse processo. 
Quadro 3 - Riscos e benefícios associados à transfusão de sangue e componentes sanguíneos

\begin{tabular}{|l|l|}
\hline Benefícios & Riscos \\
\hline - Transfusão de eritrócitos indicada em & - Erro que conduz à transfusão incorreta, que \\
paciente com diminuição da capacidade de & pode resultar numa reação transfusional grave \\
transporte de oxigénio. & em razão de incompatibilidade ABO. \\
- Transfusão de plaquetas para tratamento ou & - Transmissão de agentes infecciosos por \\
prevenção de hemorragias em pacientes com & transfusão. \\
déficits quantitativos e qualitativos & - Lesão pulmonar aguda relacionada com a \\
de plaquetas. & transfusão. \\
- Transfusão de plasma e crioprecipitado & - Outras reações transfusionais. \\
para profilaxia ou tratamento de déficits & - Infeção bacteriana por conta de componentes \\
congénitos de factores da coagulação. & sanguíneos contaminados. \\
& - Sobrecarga volémica. \\
\hline
\end{tabular}

Fonte: Adaptado de Australian Red Cross Blood Service (2012).

O erro humano tem sido identificado como uma das principais fontes das fatalidades relacionadas com transfusões de incompatibilidade $\mathrm{ABO}$. A incompatibilidade $\mathrm{ABO}$ corresponde a uma reação grave do sistema imunitário do paciente em razão da transfusão de componente sanguíneo cujo grupo é diferente e incompatível com o dele.

Nos EUA, a frequência de mortes evitáveis por transfusão, atribuídas à identificação errada da amostra de sangue pré-transfusional da unidade de sangue ou do destinatário, varia de 1:600.000 transfusões a 1:800.000 (Krombach et al. 2002).

Num estudo realizado entre 1996 e 1999 pelo SHOT (Serious Hazards Of Transfusion - Sistema de Hemovigilância do Reino Unido), verificou-se uma incidência de erro de 1:16.000 (335 erros por 5,5 milhões de unidades de concentrado de eritrócitos transfundidas entre 1996 e 1999). Concluiu, também, que os erros referentes à transfusão ABO incompatíveis eram responsáveis por $54 \%$ de todas as complicações relacionadas com a transfusão e, ainda, colocaram a condição de vida do paciente em risco 97 vezes, conduzindo a 4 mortes (1:1.400.000 transfusões) e a 29 casos de morbilidade major/morbidade imediata (1:200.000 transfusões) (Krombach et al. 2002).

No relatório do SHOT de 2012, os eventos adversos causados por erros continuam a ser os mais frequentes, sendo a transfusão do componente sanguíneo incorreto o erro mais notificado (SHOT 2013).

Em 2015, o relatório do SHOT refere a existência de 26 mortes, das quais oito eram preveníveis. Revela que o risco de morte associada à 
transfusão causada por erro é de 1:320 000. Refere, também, que 166 pacientes sofreram danos graves, sendo que um em cada três eram preveníveis.

Verifica-se, portanto, que, atualmente, o risco transfusional prioritário é o relacionado com erros transfusionais que podem ocorrer ao longo de todo o processo.

O processo transfusional é um complexo e envolve muitos intervenientes/atores e procedimentos, englobando um conjunto de pontos críticos em que há a efetiva possibilidade de ocorrência de erro. E embora haja reações que derivam de complicações inevitáveis, na sua grande maioria, essas devem-se a erros humanos, e como tal evitáveis.

A cadeia transfusional corresponde ao conjunto de etapas que envolvem o processo transfusional (Figura 8), estendendo-se desde o recrutamento e seleção do dador/doador até a administração e monitorização da transfusão no paciente.

Podemos considerar duas abordagens do processo transfusional: a primeira na perspetiva do dador/doador; e a segunda na perspetiva do paciente.

Figura 8 - Etapas do processo transfusional

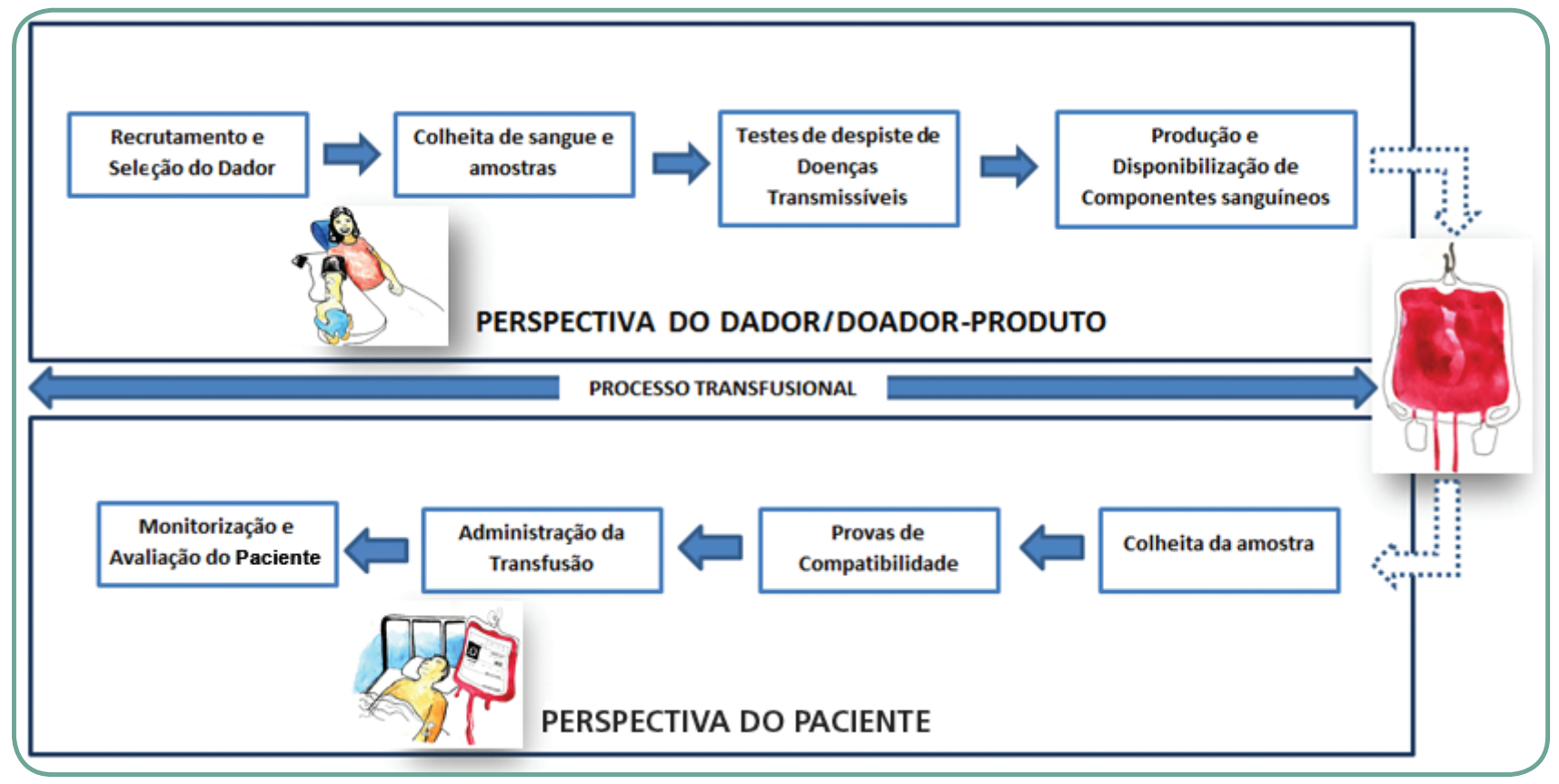

Fonte: Adaptado de Klein (2010). 
Na transfusão de sangue, a segurança do paciente depende da segurança do produto sanguíneo e da segurança do processo clínico de transfusão. A OMS classifica os incidentes transfusionais em dois grupos:

1. Aqueles que estão diretamente relacionados com o sangue e componentes sanguíneos, e

2. Aqueles que estão relacionados com o processo transfusional (OMS 2010).

Há três áreas no processo de transfusão (excetuando a segurança do sangue - produto), que são propícias a erros (Figura 9). A primeira área onde há possibilidade de ocorrência de erro é referente à decisão de transfundir, seguida da colheita/coleta de amostras para testes pré-transfusionais, e finalmente à administração da transfusão ao paciente (Dzik 2006).

Figura 9 - Potenciais áreas de erro do processo transfusional na perspetiva do paciente

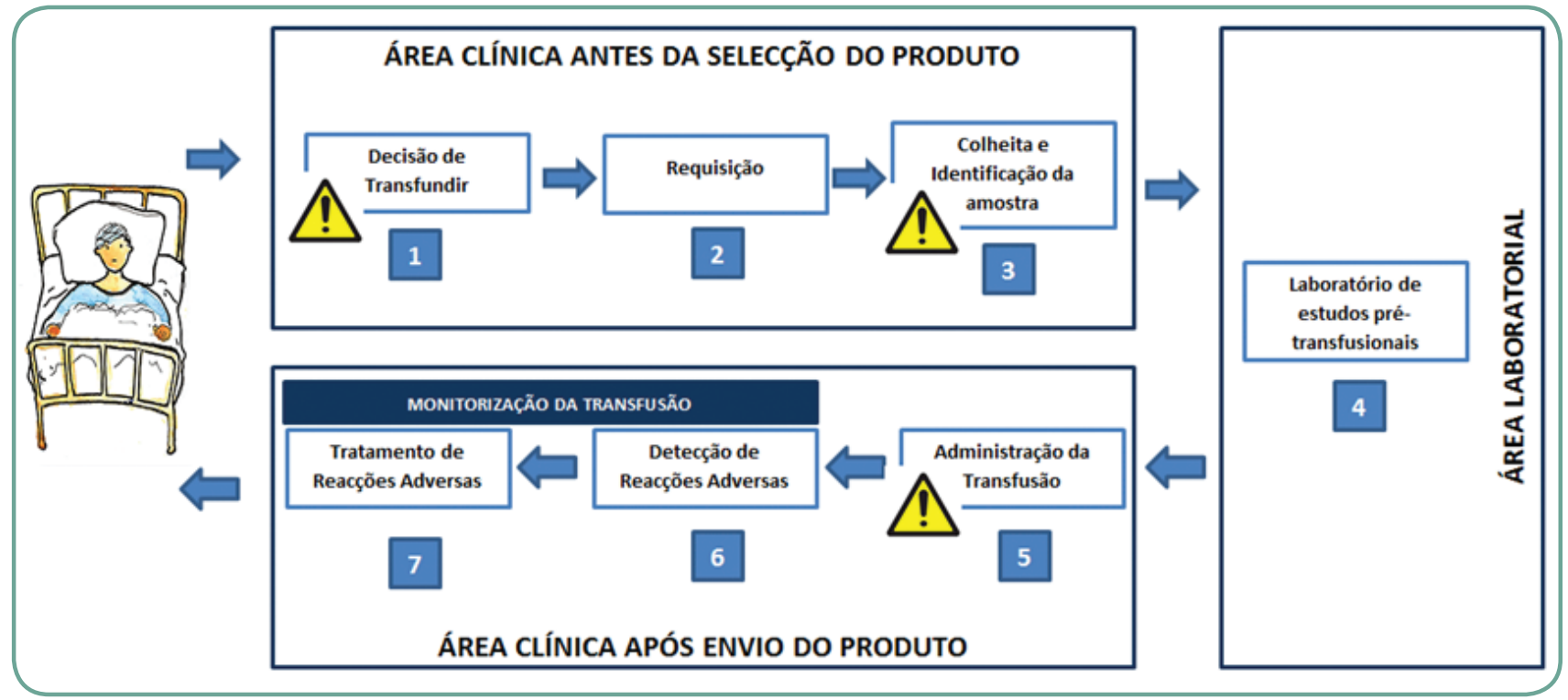

Fonte: Adaptado de Dzik (2006).

Na figura acima indicada, os momentos críticos do processo transfusional, em que erros podem ocorrer, estão marcados com a sinalética/ sinalização de atenção (triângulo amarelo). É fundamental que esses passos sejam efetivamente controlados para garantir a segurança dos pacientes e prevenir incidentes e eventos adversos evitáveis. O objetivo é promover a melhoria da qualidade do processo transfusional, isto é, a transfusão da unidade certa para o paciente certo no momento certo e nas condições certas e, ainda, de acordo com as diretrizes (guidelines) apropriadas. O que se pretende é uma utilização segura do sangue, clinicamente eficaz e eficiente (OMS 2010). 


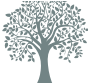

A nomenclatura dos eventos adversos em transfusão tem características particulares. Daí que se recomenda a leitura das definições propostas pelo ISBT em 2011 e 2015. http://www.isbtweb. org/fileadmin/user_upload/ WP_on_Haemovigilance/ISBT_ definitions_final_2011_4_. pdf

http://www.isbtweb.org/ fileadmin/user_upload/ISBT_ definitions_sentinel_events_adopted2015.pdf

É recomendada a leitura das definições propostas para os eventos adversos em transfusão pelo SHOT em 2017.
Vários são os incidentes decorrentes de transfusão. Segundo o SHOT, são considerados incidentes os decorrentes de vários tipos de erros que ocorrem ao longo do processo transfusional (SHOT 2013). Assim são considerados incidentes em transfusão:

㫫 a transfusão do componente sanguíneo incorreto;

路 transfusão de componente sanguíneo incorreto por requisitos especiais não conhecidos;

橉 transfusão evitável, atrasada ou subtransfusão;

瞵 erros de manipulação e armazenamento;

橉 sangue certo no paciente correto, mas com falhas de identificação.

Alguns desses incidentes podem resultar numa reação transfusional adversa para o paciente, nomeadamente numa reação hemolítica por incompatibilidade $\mathrm{ABO}$. A incompatibilidade $\mathrm{ABO}$ representa uma das ameaças mais temíveis em medicina transfusional, uma vez que pode causar a morte do paciente. Em geral, é o resultado de várias falhas que ocorreram ao longo da cadeia transfusional e não foram identificadas atempadamente (antes da transfusão se iniciar). Está, geralmente, associada à incorreta identificação da amostra e/ou do paciente.

A Joint Commission on the Accreditation of Healthcare Organizations (JCAHO) realizou um estudo em que, ao longo de três anos, avaliou os near misses, tendo identificado 12 casos relacionados com reações transfusionais, e 10 desses resultaram em morte. Onze dos casos descritos foram reações hemolíticas, das quais oito resultaram de verificações incompletas do paciente e do sangue, e os restantes três casos foram originados pela manipulação e processamento de amostras, ou unidades de sangue, em mais de um paciente ao mesmo tempo e no mesmo local (JCAHO 2003).

A análise de incidentes (Incorrect Blood Component Transfusion - IBCT) relatados pelo SHOT em 2003 revelou que aproximadamente 50\% dos incidentes ocorreram por vários erros ou falhas no processo transfusional. Em segundo lugar, cerca de 70\% dos erros ocorreram nas áreas clínicas, e o erro mais frequente $(27 \%)$ ocorreu por uma falha pré-transfusional à cabeceira do paciente, onde se deve assegurar que o sangue certo deve ser administrado ao paciente certo (Stainsby et al. 2005).

De acordo com um estudo SHOT, realizado entre 1996 e 2008, que reflete os perigos reais da transfusão, verificou-se que, em 5.374 casos revistos, 2.355 das reações adversas ocorreram por transfusão do componente errado, e as restantes 3.019 foram diluídas por 13 categorias de incidentes e reações adversas (European Union 2010). 
A identificação incorreta do paciente é uma causa importante de eventos adversos evitáveis em todas as áreas da prática clínica, não só em medicina transfusional. Num período de 12 meses, entre fevereiro de 2006 e janeiro de 2007, a National Patient Safety Agent (NPSA) do Reino Unido recebeu 24.382 relatórios de pacientes com erros ou falhas na identificação. Um exemplo de evento adverso causado por erros de identificação durante a cadeia transfusional é a administração do componente sanguíneo ao paciente errado ou na quantidade errada. Em tais situações, foram identificados como principais factores que podem causar ou criar predisposição a erros os seguintes aspetos:

滕 intervenções realizadas em diversos locais;

噒 por membros diferentes da equipa;

蝶 em turnos/plantões diferentes;

滕 falhas de comunicação (European Union 2010).

\section{Para refletir}

Você tem conhecimento de casos de incidentes envolvendo a cadeia transfusional em seu serviço ou organização de saúde? Como é que sua organização tem lidado com essas questões e o que tem sido feito para evitá-las?

Várias têm sido as medidas preventivas sugeridas para a redução desses erros. São disso exemplos, a utilização de pulseira com código de barras de identificação do paciente e a realização de testes de compatibilidade à cabeceira do paciente, antes da administração da transfusão. Outra das sugestões refere-se à utilização de barreiras físicas, como a colocação do componente num saco que só pode ser aberto após a leitura do código de barras da pulseira do paciente. A formação dos profissionais e sua consciencialização/conscientização são essenciais, bem como a implementação de procedimentos adequados de verificação durante todo o processo e, em especial, à cabeceira do paciente. O uso das tecnologias de informação como sistema de apoio a detetar erros e a emitir alertas é também uma mais-valia para melhorar a segurança transfusional. Não obstante, entende-se que nenhuma dessas medidas pode ser considerada a ideal para todos os casos, pois é necessário avaliar qual a mais adequada para cada organização (e situação). Parece, no entanto, ser consensual que são necessárias mais evidências para comprovar a efetividade e a eficiência das várias medidas e seu real impacte na eliminação ou diminuição dos erros na transfusão (Murphy et al. 2007). 


\section{Considerações finais}

Em síntese, as questões das quedas, das úlceras por pressão e dos erros transfusionais têm assumido, por parte dos responsáveis da saúde, crescente preocupação, quer por apresentarem elevada frequência (por exemplo, as quedas são o incidente mais relatado pelos profissionais de saúde), quer pelo impacte que têm. São múltiplos os factores que estão na sua origem (causas multifactoriais), e as estratégias que visam mitigar ou eliminar tais ocorrências também têm de ser adaptadas a essa diversidade. As consequências das quedas, das UP e dos erros transfusionais podem ter impacte clínico, económico e social muito significativo não só para os pacientes e familiares, mas também para os profissionais e organizações de saúde. De acordo com alguns autores, por exemplo, as quedas podem ser prevenidas até $30 \%$ se for realizada uma correta avaliação e gestão do risco.

Por último, o relato dessas ocorrências é fundamental para analisar as condições em que ocorreram os incidentes, permitindo quantificar sua frequência e tipologia (magnitude do problema e definir prioridades de intervenção) e, acima de tudo, possibilitar a aprendizagem e o conhecimento. Dessa forma, será possível diminuir ou evitar que situações idênticas ocorram no futuro.

\section{Referências}

Almeida R, Abreu C, Mendes A. Quedas em doentes hospitalizados: contributos para uma prática baseada na prevenção. Rev Enferm Referência. 2010 dez [citado 2013 out. 17]; Série 3(2):163-72. Disponível em http://www.scielo.oces.mctes.pt/pdf/ref/v3n2/v3n2a17.pdf

Anthony D. et al. Do risk assessment scales for pressure ulcers work. J Tissue Viability. 2010 [citado 2013 set 10]:132-5. Disponível em: http://www.sciencedirect.com/science/article/pii/ S0965206X09000588

Australian Red Cross Blood Service. Annual report 2011-2012. Sidney: The Service; 2012.

Bennett G, Dealey, C, Posnett J. The cost of pressure ulcers in the UK. Age Ageing. 2004 [citado 2013 set 27];33(3):230-5. Disponível em: http://ageing.oxfordjournals.org/content/33/3/230.long

Black J, Edsberg LE, Baharestani MM, Langemo D, Goldberg M, McNichol L, et al. Pressure ulcers: avoidable or unavoidable? Results of the National Pressure Ulcer Advisory Panel Consensus Conference. Ostomy Wound Manage. 2011 [citado 2013 set 10];57(2):24-37. Disponível em: http://www.npuap.org/wp-content/uploads/2012/01/A-UA-pr-ul1.pdf

Brem H, Maggi J, Nierman D, Rolnitzky L, Bell D, Rennert R, et al. High cost of stage IV pressure ulcers. Am J Surg. 2010 Oct [citado 2013 set 27];200(4):473-477. Disponível em: http://www.ncbi. nlm.nih.gov/pmc/articles/PMC2950802/pdf/nihms199415.pdf

Calman K. Cancer: science and society and the communication of risk. Br Med J. 1996;313:801.

Chaudhary R. Rationale use of blood components. Indian J Transf Med. 2011. Disponível em: http:// ijtm.in/view_article.php?id=16 
Dealey C, Posnett J, Walker A. The cost of pressure ulcers in the United Kingdom. J Wound Care. 2012;21(6):261-66.

Delgado M. A melhoria contínua da qualidade. In: Campos L, Borges M, Portugal R. Governação dos hospitais. Alfragide: Casa das Letras, 2009. p. 45-55.

Demarré L, Van Lancker A, Van Hecke A, Verhaeghe S, Grypdonck M, Lemey J, Annemans L, Beeckman D. The cost of prevention and treatment of pressure ulcers: a systematic review. Int J Nurs Stud. 2015 Nov;52(11): 1754-74.

Dzik S. Non-infectious serious hazards of transfusion. Blood Develop. 2002; 17:1-4.

Dzik WH. New technology for transfusion safety. Br J Haematol. 2006: 181-90.

European Pressure Ulcer Advisory Panel. International guideline: prevention of pressure ulcers: quick reference guide. Washington DC: EPUAP/NPUAP; 2009 [citado 2013 set 9]. Disponível em: http:// www.epuap.org/guidelines/Final_QuickTreatment.pdf.

European Network for Safety among Elderly. Fact sheet: prevention of falls among elderly. Athens: EUNESE, 2006 [citado 2013 out 18]. Disponível em: http://www.injuryobservatory.net/wp-content/ uploads/2012/08/Older-Guide-Prevention-of-Falls.pdf.

European Union. Project optimal blood use. Bruxelles: EU; 2010.

France D, Slayton J, Moore S, Domenico H, Matthews J, Steaban RL, et al. A multicomponent fall prevention strategy reduces falls at an Academic Medical Center. Jt Comm J Qual Patient Saf. 2017 Sept;43(9):460-70

Ganz D, et al. Preventing falls in hospitals: a toolkit for improving quality of care. Rockville: Agency for Healthcare Research and Quality, 2013 [citado 2013 out 20]. Disponível em: http://www.ahrq. gov/professionals/systems/long-term-care/resources/injuries/fallpxtoolkit/index.html.

Joint Commission on Accreditation Healthcare Organization. Blood transfusion errors: preventing future occurrences. Oakbrook Terrace (III): JCAHO; 2003. Retrieved from Pratice Alert:29.

Kiely P, Gambhir M, Cheng AC, McQuilten ZK, Seed CR, Wood EM. Emerging infectious diseases and blood safety: modeling the transfusion-transmission risk. Transfus Med Rev. 2017 July;31(3):154-64.

Klein H. How safe is blood, really? Biologicals. 2010;38:100-4.

Klein $\mathrm{H}$, et al. Pathogen inactivation: making decisions about new techonologies - report of a consensus conference. Transfusion. 2007: 47:2338-47.

Krombach J, et al. Human error: the persisting risk of blood transfusion: a report of five cases. Anesth Analg. 2002.

Makai P, Koopmanschap M, Bal R, Nieboer AP. Cost-effectiveness of a pressure ulcer quality collaborative. Cost Eff Resour Alloc. 2010 [citado 2013 set 11];8:11-24. Disponível em: http:// www.resource-allocation.com/content/pdf/1478-7547-8-11.pdf

Margato C, Miguéns C, Ferreira P, Gouveia J, Furtado K. Escala de Braden para avaliação de risco de úlceras por pressão. Versão validada para Portugal. [local desconhecido: editora desconhecida]; 2001.

McFarlane-Kolb H. Falls risk assessment, multitargeted interventions and the impact on hospital falls. Int J Nurs Pract. 2004 May [citado 2013 out 19];10:199-206. Disponível em http:// onlinelibrary.wiley.com/doi/10.1111/j.1440-172X.2004.00482.x/pdf.

McGuinness J, Persaud-Roberts S, Marra S, Ramos J, Toscano D, Policastro L, et al. How to reduce hospital-acquired pressure ulcers on a neuroscience unit with a skin and wound assessment team. Surg Neurol Int. 2012 [citado 2013 set. 17]; 3(1):138. Disponível em: http://www. surgicalneurologyint.com/temp/SurgNeurollnt31138-3771742_102837.pdf 
Miake-Lye IM, Hempel S, Ganz DA, Shekelle PG. Inpatient fall prevention programs as a patient safety strategy: a systematic review. Ann Intern Med. 2013 Mar 5 [citado 2013 out 20]. Disponível em: http://annals.org/article. aspx?articleid $=1656443$.

Ministério da Saúde (PT), Direção Geral da Saúde. Úlceras por pressão. Lisboa: MS, DGS, 2011 [citado 2013 set 9]. Disponível em http://www.dgs.pt/ms/8/pagina. aspx? codigoms=5521\&back=1\& codigono=001100150176AAAAAAAAAAAA.

Morse J. Preventing patient falls: establishing a fall intervention program. 2nd ed. New York: Springer Publ.; 2009.

Murphy MF, et al. Prevention of bedside errors in transfusion medicine (PROBE-TM) study: a cluster-randomized, matched-paired clinical areas trial a simple intervention to reduce errors in the pretransfusion bedside check. Transfusion 2007 May; 47:771-80.

National Blood Authority. 2013 [citado 2013 fev 12]. Disponível em: http://www.blood.gov.au

National Health Service, Patient Safety First (UK). The "How to guide" for reducing harm from falls. London: NHS, PSF; 2009 [citado 2013 out 17]. Disponível em: http://www.patientsafetyfirst.nhs.uk/ ashx/Asset.ashx?path=/Intervention-support/FALLSHow-to\%20Guide\%20v4.pdf.

National Institute for Health and Care Excellence. Falls: assessment and prevention of falls in older people. London: NICE; 2013 [citado 2013 out 20]. (NICE clinical guideline, 161). Disponível em: http://www.nice.org.uk/nicemedia/ live/14181/64088/64088.pdf.

National Patient Safety Agency, National Health Service (UK). Slips, trips and falls in hospital: the third report from the patient safety observatory. London: NPSA, NHS, 2007 [citado 2013 out 17]. Disponível em: http://www.nrls.npsa.nhs.uk/resources/?entryid45=59821.

Oliver D, et al. Risk facts and risk assessment tools for falls in hospital in-patients: a systematic review. Age Ageing. 2004 [citado 2013 out 17];33:122-33. Disponível em: http://ageing. oxfordjournals.org/content/33/2/122.long.

Organização Mundial da Saúde. Processo de Transfusão médica e segurança de pacientes. Genebra: OMS, 2010 [citado 2014 jun 25]. Disponível em: http://www.who.int/bloodsafety/clinical_use/who_ eht_10_05_pt.pdf

Peña J, Dzik W. Utilization management in the blood transfusion service. Clin Chim Acta. 2014:427:178-82. Dora

Pieper B, Langemo DE, Cuddigan J. Pressure ulcer pain: a systematic literature review and national pressure ulcer advisory panel white paper. Ostomy Wound Manage. 2009 Feb [citado 2013 set 9];55(2):16-31. Disponível em: http://www.npuap.org/wp-content/uploads/2012/01/Pieper_2009_ Feb1.pdf.

Posnett J, Franks P. The burden of chronic wounds in the UK. Nurs Times. 2008 [citado 2013 set 27]:44-5. Disponível em http://www.nursingtimes. net/the-burden-of-chronic-wounds-in-theuk/573423.article.

Potter P, Allen K, Costantinou E, Klinkenberg WD, Malen J, Norris T, et al. Evaluation of sensor technology to detect fall risk and prevent falls in acute care. Jt Comm J Qual Patient Saf. 2017 Aug;43(8):414-21

Pshegubj. My first earnings cheque. Flick, 2010 [citado 2014 jul 21]. Disponível em: http://www. flickr.com/photos/pshegubj/5161075477/.

Rhodes B. Ficheiro:Communitive midshaft humeral fracture callus.jpg. Wikipedia, 2004 [citado 2014 jul 21]. Disponível em: http://pt.wikipedia.org/wiki/Ficheiro:Communitive_midshaft_humeral_ fracture_callus.jpg.

Saraiva D, et al. Quedas: indicador da qualidade assistencial. Nursing. 2008 Jul;235:28-35. 
Sardo PMG, Guedes JAD, Alvarelhão JJM, Machado PAP, Melo EMOP. Pressure ulcer incidence and Braden subscales: Retrospective cohort analysis in general wards of a Portuguese hospital. J Tissue Viability. 2018 May [citado 2019 jan 20];27(2):95-100. Disponível em: https://www.sciencedirect. com/science/article/pii/S0965206X17300499?via\%3Dihub

Schwendimann R, et al. Falls and consequent injuries in hospitalized patients: effects of an interdisciplinary falls prevention program. Bio Med Central. 2006 Jun [citado 2013 out 18];6(69):1-7. Disponível em: http://www.ncbi.nlm.nih.gov/pmc/articles/PMC1534028/pdf/1472-6963-6-69.pdf.

Serious Hazards of Transfusion SHOT. Annual SHOT Report 2012. London: SHOT; 2013.

Serious Hazards of Transfusion SHOT. Annual SHOT report 2015. London: SHOT; 2015. Dora

Serious Hazards of Transfusion SHOT. SHOT Definitions of current categories \& what to report. Revised 2017. Manchester: SHOT; 2017 [citado 2019 jan 20]. Disponível em: https://www.shotuk. org/wp-content/uploads/SHOT-Definitions-Update-2017-FINAL-2.pdf

Skelton D, Todd C. What are the main risk factors for falls amongst older people and what are the most effective interventions to prevent these falls? Copenhagen: Health Evidence Network, WHO Regional Office for Europe, 2004 Mar [citado 2013 out 20]. Disponível em: http://www.euro.who. int/_data/assets/pdf_file/0018/74700/E82552.pdf.

Slawomirski L, Auraaen A, Klazinga N. The economics of patient safety: strengthening a valuebased approach to reducing patient harm at national level. [place unknown]: OECD; 2017.

Stainsby D, et al. Reducing adverse events in blood transfusion. Br J Haematol. 2005:131.

Sullivan N, Schoelles K. Preventing in facility pressure ulcers as a patient safety strategy. Ann Intern Med. 2013 [citado 2013 set 10]: 410-6. Disponível em: http://annals.org/article. aspx? articleid=1657885.

World Health Organization, Department of Essencial Health Tecnologies. Blood transfusion safety. Geneve: WHO; 2006.

World Health Organization, Department of Essencial Health Tecnologies. Blood transfusion safety. Geneva: WHO; 2006.

World Health Organization. Falls. Genéve: WHO; 2012 Oct [citado 2013 out 21]. (Fact sheet; n. 344). Disponível em: http://www.who.int/mediacentre/factsheets/fs344/en/.

The Yorck Project. Ficheiro:Vincent Willem van Gogh 002.jpg. Wkipedia, 2005 [citado 2014 jul 21]. Disponível em: http://pt.wikipedia.org/wiki/Ficheiro:Vincent_Willem_van_Gogh_002.jpg. 